\title{
External placements: a potentially valuable addition to higher training in old age psychiatry
}

\author{
Peter Bentham and Abdul Patel
}

This article briefly describes the experlence of two final year senior registrars visiting services in other regions. The potential training benefits of such external placements for higher trainees are outlined and practical suggestions are made on how to make them more widely avallable.

Many psychiatrists have only very limited exposure to old age psychiatry during their training and it is common to find consultants in old age psychiatry with a minimum experience of three specialist placements, one at trainee level and a further two as a higher trainee.

The Joint Committee on Higher Psychiatric Training (JCHPT), published a handbook (1995) describing requirements and standards for speciality training. The guidelines on the requirements for approval of higher training schemes in the psychiatry of old age recommend that placements should allow involvement in: service planning; multidisciplinary assessment, treatment and support of patients in various settings utilising a range of facilities; liaison with geriatric medicine, primary care and collaboration with social service and voluntary organisations.

The JCHPT guidelines state that the two psychogeriatric years should include experience with two different psychogeriatric teams and trainers and, as far as possible, these should be complementary and contrasting experiences. In practice however, placements are commonly within the same region and occasionally within the same district or Trust, where models of service provision and styles of practice are similar. The present training system frequently offers only a very limited opportunity to experience the rich diversity of excellent old age psychiatric practice avallable in the UK today.

The authors have been privileged to work with forward-thinking trainers who have attempted to address this problem by providing the opportunity for their senior registrars to visit services in other regions for limited periods of up to two weeks. Having survived the first two years as consultants wiser and otherwise relatively unscathed, we believe that the knowledge and experience gained from these external placements has been invaluable in developing our own fledgling services. External placements appear to offer a number of benefits at relatively little cost.

Higher trainees seeking consultant appointments are aware of Royal College guidance on resource provision. External placements enable trainees to observe how this guidance works in practice in different geographical areas, in particular resource requirements may be very different in rural and urban areas. It is well known that there is considerable overlap between psychiatric. geriatric and social services for the elderly, however, there are few better ways of understanding how differing views on service responsibility and joint working affect service provision than observing this directly. Offering higher trainees the opportunity of systematically evaluating a variety of services, allows them to obtain the necessary experience to make a truly informed choice about the most suitable consultant job in the future.

External placements on carefully selected units provide an unparalleled opportunity to meet face to face with well-read academics and charismatic service innovators, enabling one to gain insight into subjects that are not readily available from publications or conference presentations. Accompanying experienced clinicians, with diverse training backgrounds in their day-to-day work, allows observation of the broad spectrum of effective assessment and management styles that have evolved.

Importantly these placements simply enable higher trainees to develop contacts in areas that would not normally be open to them. Good models of virtually every form of service for the elderly mentally ill are avallable for inspection in the UK today. If your interest is in assessment day-hospitals, then a visit to the Newcastle Brighton Clinic would be invaluable, the more community orientated might wish to experience a community clinic in central Manchester or south Birmingham. Academic memory clinics abound, 


\section{EDUCATION}

but visiting the Cardiff Community Memory Clinic, which has a strong service orientation, provides a different perspective.

External placements provide an excellent opportunity to conduct research, particularly in areas such as service provision (Dening, 1992) and clinical practice (Wattis et al, 1994). Placements in specialist research units and clinics provide exposure to experimental assessment techniques and treatments that would not be available locally.

The quality of joint working arrangements between old age psychiatry, geriatric medicine and social services varies considerably throughout the country, however, good models are readily accessible. Innovative schemes linking old age psychiatry with voluntary and charitable organisations, such as the MIND Extended Community Care Scheme in Southampton are less common and worth seeing.

The disadvantages of external placements are few and can easily be overcome. First there is the time factor. Higher trainees are supposed to be supernumerary in a service sense and if placements are short then duty rotas can easily be adjusted. Special interest sessions could be utilised flexibly to provide short block attachments of one or two weeks. Obtaining travel and accommodation expenses is more difficult as trusts may be reluctant to provide funding. however, in our experience basic accommodation has been relatively easy to obtain at fairly low cost. Consultants are now busier than ever and may find it difficult to make all the necessary arrangements. The higher trainee can, however, actively involve himself in the process if initial contact is made at a senior level. It is important that clear aims and objectives are initially set for visits and information should be subsequently logged in a systematic way for future reference. Makding reciprocal arrangements with old friends and colleagues seems to work particularly well.

Gerlatric medicine placements have now become an integral part of higher training in old age psychiatry and are generally seen as beneficlal (Manchip, 1994). The authors found external placements in old age psychiatry as part of the final year one of the most useful components of their senior registrar training. We would recommend that wider use is made of this valuable training experience and have encouraged local higher trainees to take the opportunity of doing so.

\section{References}

DENING, T. (1992) Community psychiatry of old age: a UK perspective. International Journal of Gerlatric Psychiatry. 7. 757-766.

Jont Commitrese on Highrer Psychatric Traning (1995) Handbook (seventh edition). OP27. London: Royal College of Psychiatrists.

MaNCHIP, S. (1994) From psychiatry to gerlatrics and back agatn. Psychiatric Bullettr, 18, 560-561.

Wattis, J., Bentram, P. \& Bestuey, J. (1994) Choice of antidepressants by psychlatrists working with old people. Psychtatric Bulletin, 18, 148-151.

*Peter Bentham, Consultant in Old Age Psychiatry: and Abdul Patel, Consultant in Old Age Psychiatry, Mental Health Services for Older Adults, Queen Elizabeth Psychiatric Hospital, Mindelsohn Way, Edgbaston, Btrmingham B15 $29 Z$

*Correspondence 